\title{
THE EFFECT OF POWER LIMBS, SPEED REACTION, FLEXIBILITY AND SELF CONFIDENCE ON THE ACHIEVEMENT OF ELITE ATHLETES ATHLETIC WEST JAVA IN THE TRACK NUMBER
}

\author{
Anggi Setia Lengkana ${ }^{1}$, James Tangkudung ${ }^{2}$, Moch. Asmawi ${ }^{3}$ \\ State university of Jakarta \\ jamestangkudung@unj.ac.id \\ mochasmawi@unj.ac.id
}

\begin{abstract}
This study aims to reveal the effect of limb power, reaction speed, flexibility and confidence in the performance of athletic elite athletes on track numbers. This research was conducted at Universitas Pendidikan Indonesia (UPI) Lab. Sport Faculty of Sport and Health Education (FPOK), with a sample of 31 athletes. The analytical technique used in this study is to use path analysis (Path Analysis), with the aim to identify the influence between variables. The results showed that: (1). Power Limbs affect the achievement of elite athletes by 51.7\%. (2). The speed of the reaction had an effect on the achievement of elite athletes by 49.3\%. (3). Flexibility has no effect on elite athletes achievement of 0.3\%. (4). Confidence affects the achievement of elite athletes by 20\%. (5). Limb power affects $40.5 \%$ confidence. (6). The speed of the reaction affects the confidence of $30.7 \%$. (7). Flexibility has no effect on confidence of $23.2 \%$.
\end{abstract}

Keywords: Performance of elite athlete, athletic, limb power, reaction speed, flexibility and self confidence

Being an athlete takes hard work from start to finish, like a serious workout and even an athlete's lifestyle should be taken care of and managed well. It is expected that with such an implementation the athlete can focus and achieve the desired target. And must have a level of skill, good physical fitness according to the sport that they do, and good psychological factors in the face of mental stress in the matches. In athletic sports especially on the track number, excellent physical condition is the main support in achievement.

When the athlete ran the power requirement of the limbs, and the reaction speed was so great, that the athlete had to make the first step toward the acceleration phase as soon as possible. When trying to set foot first, start the phase of acceleration and when running, it takes strong and fast thrust of the leg movement, to keep the speed to remain stable. Through good power the reaction speed will be good too, power is the result of times between strength and speed. For that exercise to increase power is given after the sportsmen trained element of strength and speed. Power exercises can improve physical functioning because it involves movement at high speed. Power exercises can improve if given from scratch so as to create better conditions with a strong reflex function.

The speed of the reaction is identical to the term reaction time. The same opinion was expressed by Johnson and Nelson. The terms reaction time and speed of reaction are used alternately to express a person's ability to provide a kinetic answer to the presence of a suddenly presented stimulus. But the reaction time is more intended to explain in terms of time, while the speed of reaction more towards the movement.

Flexibility is one of the important elements in the framework of sports development achievement because the level of quality of one's flexibility will affect other biomotor components. Flexibility exercises such as stretching improve the range of motion of muscles and joints. That, flexibility exercises such as stretching increase the range of muscle and joint motion. So it can affect 
the technique of running athletes. While confident, it is often referred to as an important part of a successful sporting performance and has been shown to affect sports behaviors, attitudes, and achievements. An athlete's self-confidence can be seen from the persistence of pursuing something when planning slips from the thought and enthusiasm shown

Based on theoretical studies, the limb power factor, reaction rate, flexibility and selfconfidence are the factors that influence elite athlete achievement on the track number. On the other hand, based on preliminary observations, the authors identified that achievement of athletic elite athlete achievement on track number is relatively unfavorable, presumably caused by variables such as limb power, reaction speed, flexibility and confidence, therefore based on the need to hold a scientific approach in the form research with themes, Power limbs, reaction speed, flexibility and confidence as well as its impact on the achievement of Athletic Athletics Athletic West Java at Track Number.

\section{METHOD}

Based on the research problem to be studied and the purpose to be achieved, the method used in this study is a survey method with causality studies or the study of causality among the variables studied. Variable in this research is endogen variable, that is achievement of elite athlete (Y), second variable is intervening variable, that is self confidence $(\mathrm{X} 4)$, and third variable is exogenous variable consisting of limb power (X1), reaction rate (X2) and flexibility (X3) Analytical technique used is path analysis approach. This model is used for analyze the pattern of relationships between variables with the aim to know between variables. Path analysis model (path analysis) in this research can be seen in the following constellation:

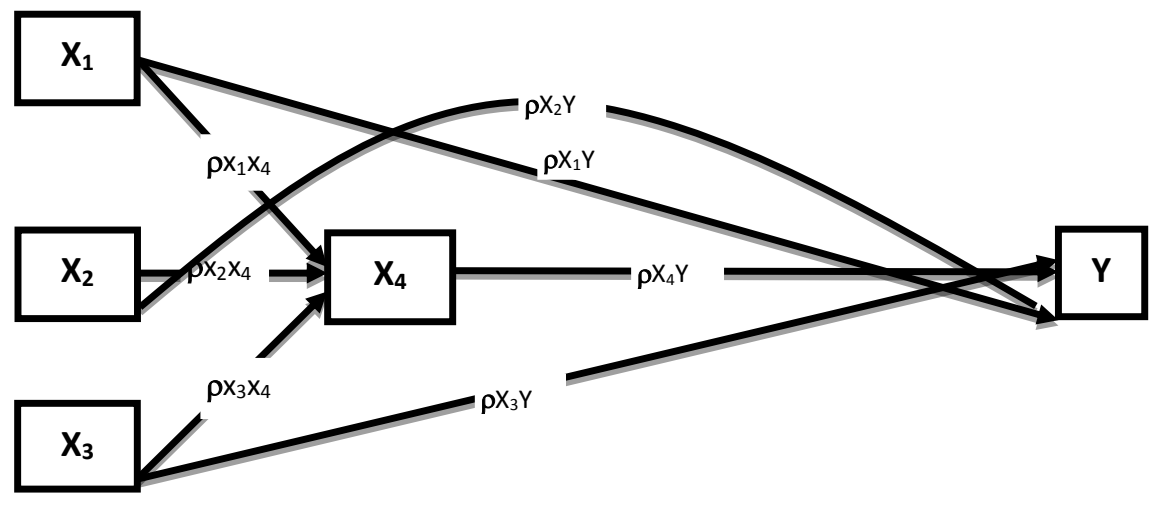

Causality Relationship of Path Coefficients

$\mathrm{X}_{1} \quad$ : limb power

$\mathrm{X}_{2}$ : reaction speed

$\mathrm{X}_{3} \quad$ : Flexibility

$\mathrm{X}_{4}$ : self confidence

$\mathrm{Y} \quad$ : Performance of elite athlete

$\rho x_{1} Y$ : Path coefficient variable $\mathrm{X}_{1}$ to variable $\mathrm{Y}$

$\rho \times 2 Y$ : Path coefficient variable $\mathrm{X}_{2}$ to variable $\mathrm{Y}$

$\rho \times 3 Y$ : Path coefficient variable $\mathrm{X}_{3}$ to variable $\mathrm{Y}$

$\rho \times 4 \mathrm{Y}$ : Path coefficient variable $\mathrm{X} 4$ to variable $\mathrm{Y}$

$\rho x_{1} x_{4}$ : Path coefficient variable $\mathrm{X}_{1}$ to variable $\mathrm{X}_{4}$

$x_{2} \times 4$ : Path coefficient variable $\mathrm{X}_{2}$ to variable $\mathrm{X}_{4}$

$\rho x_{3} x_{4}$ : Path coefficient variable $\mathrm{X}_{3}$ to variable $\mathrm{X}_{4}$ 
Population in this research is all athletic elite athletes of West Java at track number. The total population is 31 athletes. Sampling technique used is Nonprobability sampling by using saturated sampling technique. The sample that researchers use is the athletic athletes athletes of West Java at track number.

In this study, the instruments used in collecting data used based on the variables involved are described as follows:

\section{Standing Broad Jump}

A standing long jump is often used as a functional test to assess leg power, but the test may underestimate the athlete's true potential if the athlete does not use the best possible technique. The selection of takeoff angle is one of the most important technique variables. Each testee is given a chance to do 2 times.

\section{Whole Body Reaction Type II Test}

Measure the reaction time of the experimental person by using Whole Body Reaction Type II Test, which is a set of measuring instruments that serve as a measure of reaction time. This measuring instrument can measure reactions both audio (with sound) and visual (with light or color).

\section{Test Modifications Sit and Reach}

The purpose of this test is to determine the flexibility of the waist and torso (togok) of a student / athlete.

\section{Confidence Test Instrumen}

The questionnaire was taken from Vealey et al, Sources of Sport-Con fi leence Questionnaire (SSCQ). SSCQ assesses the source of sports confidence in athletes. SSCQ consists of 41 items representing nine unique confident sources in the context of competitive sport: (1) Mastery, (2) Demonstration Of Ability, (3) Mental And Physical Preparation, (4) Physical Self-Presentation, (5) Social Support, (6) Coach's Leadership, (7) Vicarious Experience, (8) Environmental Comfort, (9) Situational Favorableness. Answers on this scale are using likerts scales. For granting that answers positive statements Strongly Agree (SS): 5, Agree (S): 4, Hesitate (R): 3, Disagree (TP): 2, Strongly Disagree (STP): 1. As for question negative, scoring otherwise.

Data analysis techniques used in this study are as follows:

1. Descriptive statistics, ie statistics that aims to provide data description of each research variable.

2. Test analysis requirements that include (1) data normality test, and (2) linearity test.

3. Path analysis to see the influence of one variable against other variables in accordance with the set.

\section{RESULTS AND DISCUSSION}

The data descriptions presented in this chapter include achievement data of Elite athletes (Y), which are endogenous variables and limb power variables (X1), Reaction Speed (X2), Flexibility (X3) and confidence (X4) as exogenous variables. These exogenous variables determine the value of endogenous variables. Among endogenous and exogenous variables there is a confident variable (X4) that is categorized as an intermediate variable. This is because the variable $\mathrm{X} 4$ in addition to affect the value of variable $\mathrm{Y}$, is also influenced by variables $\mathrm{X} 1, \mathrm{X} 2$ and $\mathrm{X} 3$.

Furthermore, the exposure of some descriptive statistics of variables X1, X2, X3, X4 and Y. 
Table 1 Descriptions of Research Results

\begin{tabular}{|c|c|c|c|c|c|}
\hline \multirow[b]{2}{*}{ Statistics } & \multicolumn{5}{|l|}{ Variables } \\
\hline & $\begin{array}{l}\text { Achievem } \\
\text { ents of } \\
\text { Elite } \\
\text { Athletes }\end{array}$ & $\begin{array}{l}\text { Power } \\
\text { Limbs }\end{array}$ & $\begin{array}{l}\text { Speed } \\
\text { Reaction }\end{array}$ & Flexibility & Confidence \\
\hline Maximum Value & 100,00 & 78,00 & 100,00 & 28,60 & 247 \\
\hline Minimum Value & 1,12 & 45,00 & 76,25 & 10,41 & 150 \\
\hline Average & 18,98 & 65,35 & 88,75 & 19,67 & 150 \\
\hline Standard deviation & 30,36 & 8,08 & 5,83 & 3,96 & 21,50 \\
\hline Number of Samples & 31 & 31 & 31 & 31 & 31 \\
\hline
\end{tabular}

\section{Hypothesis Testing}

Hypothesis testing is done to determine the direct and indirect influence between variables. The proposed hypothesis will be concluded through the calculation of path coefficient and significance for each path under study. The result of the decision on all the proposed hypotheses is described as follows.

\section{Power Limbs (X1) Influential Against Achievement Elite Athlete (Y)}

Hypothesis testing is done to prove that Power Limb (X1) effect on achievement Elit Athlete

(Y). The hypotheses tested are as follows:

H0: $\rho Y X 1=0$

$\mathrm{H} 0: \rho \mathrm{YX} 1>0$

Based on the data analysis it is identified that the tcount (3.251) is greater than the ttable (1.697), so the path coefficient is significant. So based on the calculations found that Power Limbs (X1) affect the achievement of Elite Athlete (Y).

\section{Reaction speed (X2) Affects Achievement of Elite Athlete (Y)}

Hypothesis testing is done to prove that Speed Reaction (X2) influence to achievement Elit Athlete $(\mathrm{Y})$. The hypotheses tested are as follows:

$\mathrm{H} 0: \rho \mathrm{YX} 2=0$

$\mathrm{H} 0: \rho \mathrm{YX} 2>0$

Based on the above data analysis it is identified that the tcount (3.053) is greater than the ttable (1.697), so the path coefficient is significant. So based on the calculation found that Speed Reaction (X2) affect the achievement of Elite Athlete (Y).

\section{Flexibility (X3) Influential Against Achievement Elite Athlete (Y)}

Hypothesis testing is done to prove that Flexibility (X3) influence to achievement Elit Athlete (Y). The hypotheses tested are as follows:

$\mathrm{H} 0: \rho Y X 3=0$

H0: $\rho \mathrm{YX} 3>0$

Based on the above data analysis it is identified that the tcount (0.018) is smaller than the ttable (1.697), so the path coefficient is not significant. So based on the calculations found that Flexibility (X3) has no effect on the achievement of Elite Athlete (Y).

\section{Confidence (X4) Influential Against Achievement Elite Athlete (Y)}


Hypothesis testing is done to prove that the confidence (X4) affect the achievement of Elite Athlete (Y). The hypotheses tested are as follows:

$\mathrm{H} 0: \rho \mathrm{YX} 4=0$

$\mathrm{H} 0: \rho \mathrm{YX} 4>0$

Based on the above data analysis, it is identified that the value of tcount (3.098 is greater than the ttable value (1.697), so the path coefficient is significant, so based on the calculation it is found that the confidence (X4) has an effect on the achievement of Elite Athlete (Y).

\section{Limb Power (X1) Affects Against Self-Confidence (X4)}

Hypothesis testing is performed to prove that Limb Power (X1) has an effect on Confidence (X4). The hypotheses tested are as follows:

$\mathrm{H} 0: \rho \mathrm{X} 4 \mathrm{X} 1=0$

$\mathrm{H} 0: \rho \mathrm{X} 4 \mathrm{X} 1>0$

Based on the above data analysis it was identified that the tcount (4.568) is greater than the ttable (1.697), so the path coefficient is significant. So based on the calculations found that Power Limbs (X1) affect the confidence (X4).

\section{Reaction velocity (X2) Affects Against Self-Confidence (X4)}

Hypothesis testing is done to prove that Speed Reaction (X2) has an effect on Confidence (X4). The hypotheses tested are as follows:

$\mathrm{H} 0: \rho \mathrm{X} 4 \mathrm{X} 2=0$

H0: $\rho \mathrm{X} 4 \mathrm{X} 2>0$

Based on the above data analysis, it is identified that the value of tcount (3.582) is greater than the value of ttable (1.697), so the path coefficient is significant. So based on the calculations found that the Speed of Reaction (X2) affect the Confidence (X4).

\section{Flexibility (X3) Influence Against Self-Confidence (X4)}

Hypothesis testing is performed to prove that flexibility (X3) has an effect on confidence (X4). The hypotheses tested are as follows:

$\mathrm{H} 0: \rho \mathrm{X} 4 \mathrm{X} 3=0$

H0: $\rho \mathrm{X} 4 \mathrm{X} 3>0$

Based on the above data analysis it was identified that the tcount (1.284) is smaller than the ttable (1.697), so the path coefficient is not significant. So based on the calculations found that Flexibility (X3) has no effect on Confidence (X4).

Based on the test results of all hypotheses that have been done in the hypothesis testing section, it can be stated that:

First, for the hypothesis there are significant influence of limb power (X1), speed of reaction (X2), flexibility (X3) to confidence (X4) after hypothesis testing individually obtained variable Flexibility (X3) not significant influence to confidence (X4) .

Second, for hypothesis there are significant influence of Power Limb (X1), Speed Reaction (X2), Flexibility (X3) and confident (X4) to achievement of Elit Athlete (Y), after hypothesis testing individually obtained variable Flexibility (X3) significant its influence on the achievement of Elite Athlete (Y). Based on the results of hypothesis testing with path analysis obtained that there is a positive influence of Speed Reaction (X2), Flexibility (X3) and confident (X4) to the achievement of Elite Athlete (Y). 
These findings indicate that to improve the performance of Elite Athlete (Y), it is necessary to consider and increase the limb power (X1), Speed Reaction (X2), Flexibility (X3) and confidence (X4).

\section{CONCLUSIONS}

Based on the results of the analysis on the Elite Athlete (Y) Achievement variables, Limb power (X1), Reaction Speed (X2), Flexibility (X3) and confidence (X4), it can be concluded that:

1. Power Limbs affect the achievement of elite athletes of $51.7 \%$.

2. The speed of the reaction affect the achievement of elite athletes of $49.3 \%$.

3. Flexibility has no effect on elite athletes achievement of $0.3 \%$.

4. Self-confidence affect the achievement of elite athletes by $20 \%$.

5. Limb power affects the confidence of $40.5 \%$.

6. The speed of the reaction affects the confidence of $30.7 \%$.

7. Flexibility does not affect the confidence of $23.2 \%$.

Based on the above conclusions and implications, the following are suggested,

1. Should increase athlete performance is done by increasing limb power, reaction speed, Flexibility and Confidence. Of these variables the most dominant effect on athlete performance is the limb power variable, the speed of reaction and confidence, therefore the coach and coach should pay attention to these factors.

2. Although in this study flexibility has no effect on athlete performance but should be noted and educated to the athlete that flexibility is crucial in achieving self-confidence and athlete achievement.

3. A comprehensive assessment of the various factors in achievement of track number athletes should be assessed, due to the limitations in this study. There are still other factors that may affect the performance of elite athletes that need to be studied further.

\section{REFERENCE}

Awoma Christopher, I. Okakah, R. O. Arainwu Gabriel (Ph.D).(2015). Facilities/Equipment As Predictor Of Sport Development In Edo State, Nigeria. European Journal of Research in Social Sciences, Vol. 3 No. 3,. ISSN 2056-5429.

Beaumont, Chris, Maynard, Ian And Butt, Joanne. (2015).Effective ways to develop and maintain robust sportconfidence: strategies advocated by sport psychology consultants. Journal of applied sport psychology, 27 (3), 301-318. Sheffield Hallam University Research Archive (SHURA).

Christopher, Awoma I. Okakah, R. O. Arainwu Gabriel (Ph. D). Facilities/Equipment As Predictor Of Sport Development In Edo State, Nigeria. European Journal of Research in Social Sciences, Vol. 3 No. 3, 2015. ISSN 2056-5429.

Côté, Jean. (2015) Sport and Family influence. They go hand in hand. (The Influence of the Family in the Development of Talent in Sport). (Northern Ireland: Queen's University)

Dahl, Kimberly Deanna. (2013), External Factors and Athletic Performance, A Senior Thesis submitted in partial fulfillment of the requirements for graduation in the Honors Program Liberty University Spring.

Hollings, Stephen C., Will G. Hopkins \& Patria A. Hume. (2012) Environmental And Venue-Related Factors Affecting Performance Of Elite Male Track Athletes. Sport Performance Research Institute New Zealand, Auckland University of Technology, Auckland, New Zealand. 